\title{
Influence of the obesogenic/leptogenic food environment on consumer behaviour in leisure centres
}

\author{
P.A. Ashworth, Y.L. Jensen, H.J. Stockton, C. Morris, S. Giove and J.R. Paxman \\ Food and Nutrition Subject Group, Sheffield Business School, Sheffield Hallam University, Sheffield, S1 1WB, UK
}

Modern environments are considered unsupportive of healthy consumer behaviours ${ }^{(1)}$, instead acting to encourage poor food choices and sedentary behaviour ${ }^{(2)}$ which can be detrimental to public health. The physical activity environment in leisure centres is inherently leptogenic, enabling energy expenditure which can promote leanness ${ }^{(3)}$. Leisure centres are considered an appropriate platform for the facilitation of leptogenic food behaviours ${ }^{(2)}$. Despite this, the food environment in leisure centres may be incongruent with the concept of a healthy lifestyle ${ }^{(4)}$. The aim of this study was to determine the nature of the food environment within leisure centres, and identify stakeholder perceptions to inform the development of strategies to encourage leptogenic food choices.

The healthiness of the vending offer was classified in South Yorkshire ( $n$ 2), West Yorkshire ( $n$ 2), and Derbyshire ( $n$ 2) leisure centres, using the Nutrient Profiling Tool (NPT). Frequently purchased items from the café were analysed in both South Yorkshire centres, using the NPT and Nutritics dietary analysis software (Nutritics Ltd, Dublin, Ireland). Semi-structured interviews with leisure centre café users ( $n$ 15), catering managers $(n 5)$, and managers $(n 6)$ were used to determine perceptions of the food environment. The interview design was informed by The Analysis Grid for Environments Linked to Obesity ${ }^{(3)}$.

\begin{tabular}{lccc}
\hline Location & 'Less healthy' vending items (\%) & 'More healthy' vending items (\%) & 'Less healthy' café items (\%) \\
\hline South Yorkshire 1 (SY1) & 67 & 33 & 20 \\
South Yorkshire 2 (SY2) & 91 & 9 & 78 \\
West Yorkshire 1 & 97 & 3 & - \\
West Yorkshire 2 & 93 & 7 & - \\
Derbyshire 1 & 82 & 18 & - \\
Derbyshire 2 & 74 & 26 & - \\
\hline
\end{tabular}

According to the NPT, the vending offer was predominantly 'less healthy' in all locations, with some availability of 'more healthy' items. In SY2, $78 \%$ of the frequently purchased café items were classified as 'less healthy', compared to $20 \%$ in SY1. This inconsistency in the food environment was reflected in the interviews. Café users reported a varied food offer, or the desire for more healthy choices. Greater visibility of leptogenic items, and information to support healthy choices, was also desired. Catering managers and managers were largely supportive of a leptogenic food environment. Perceived consumer demand, and the challenge of presenting nutritional information were considered barriers.

Stakeholder support means that leisure centres have the opportunity to become a good platform for supporting leptogenic food choices. Strategies could be implemented to increase awareness of more leptogenic items, and enable the food environment to become more educational and supportive of healthy behaviours.

1. Townshend TG \& Lake AA (2009) Health Place 15, 909-916.

2. Carter M, Signal L, Edwards R et al. (2013) BMC Public Health 13, 1-7.

3. Swinburn B, Egger G \& Raza F (1999) Prev Med 29, 563-570.

4. Nowak M, Jeanes Y \& Reeves S (2012) Nutrition \& Food Science 42, 307-314. 